\title{
CIÊNCIAS EXATAS E DA TERRA
}

A receptividade de estudantes do Ensino Fundamental frente a sequências de Atividades Didáticas computacionais para o ensino de Geometria e Desenho Geométrico

\section{The receptivity of elementary school students from the sequences of Didactic Activities for computing the teaching of Geometry and Geometric Design}

Vaneza De Carli Tibulo"; Ricardo Andreas Sauerwein ${ }^{1}$

\section{RESUMO}

O presente artigo tem como objetivo investigar e avaliar a receptividade de duas sequências de Atividades Didáticas (AD) baseadas em Tecnologias de Informação e Comunicação (TIC), para o ensino de conceitos geométricos e desenvolvimento de competências. A investigação ocorreu durante a implementação das $A D$ ao longo do ano de 2015 com 186 estudantes dos anos finais do Ensino Fundamental de uma instituição pública federal de ensino básico no Rio Grande do Sul. A análise dos questionários respondidos durante e ao final das sequências indicam que as $A D$ podem ser incorporadas de maneira permanente na prática escolar constituindo assim uma possível alternativa para situações em que se deseja incorporar aplicativos de geometria dinâmica como o Geogebra nos anos finais do Ensino Fundamental.

Palavras-chave: Atividades Didáticas computacionais; Geometria, Desenho Geométrico; Geogebra.

\begin{abstract}
This article aims to investigate and evaluate the responsiveness of two sequences of didactic activities (AD) based on Information and Communication Technologies (TIC), for the teaching of concepts and geometric skills development. The research occurred during the implementation of AD throughout the year of 2015 with 186 students of final years of basic education in a public institution of basic education in Rio Grande do Sul. The analysis of the questionnaires answered during and at the end of the sequences indicate that the $A D$ can be incorporated permanently in the school practice is therefore a possible alternative for situations in which you want to incorporate applications of dynamic geometry as the Geogebra in the final years of basic education.
\end{abstract}

Keywords: Didactic Activities computational; Geometry; Geometric Design; Geogebra.

${ }^{1}$ UFSM - Universidade Federal de Santa Maria, Santa Maria/RS - Brasil. 


\section{INTRODUÇÃO}

Os estudantes cada vez mais cedo estão chegando a nossas escolas com domínio dos mais diversos recursos digitais disponíveis ao seu redor, segundo Prensky (2001). Mas este domínio nem sempre é explorado em caráter didático, ou seja, em função do aprimoramento da aprendizagem nas escolas.

Um problema identificado na prática pedagógica como pesquisadora/professora de Matemática (Geometria e Desenho Geométrico) nos anos finais do Ensino Fundamental e que, acreditamos, e partilhado por muitos outros colegas, poderia ser formulado da seguinte maneira: Como estimular os estudantes a usar as Tecnologias da Informação e Comunicação (TIC) para aprender Matemática? Naturalmente, há muitos encaminhamentos possíveis, não mutuamente exclusivos, para esta questão uma vez que o objetivo desejado em aprender Matemática é muito amplo. Fazem parte do campo de competências e conhecimentos matemáticos propriedades aritméticas, comportamento de funções, conceitos geométricos, desenho geométrico, equações diferenciais, matrizes, análise estatística, etc. Para cada um dos tópicos citados há recursos computacionais que podem ser utilizados para facilitar o processo de aprendizagem. Muito provavelmente, o conhecimento matemático aprendido na formação escolar será utilizado na vida profissional através de um recurso computacional. Acreditamos que este último aspecto é de fundamental importância. Logo, a introdução do computador nos anos finais do Ensino Fundamental e no Ensino Médio também deve promover o desenvolvimento de competências específicas no domínio de ferramentas computacionais. Quaisquer atividades que propiciem, simultaneamente, facilitar a aprendizagem de tópicos do conteúdo programático de Matemática e o desenvolvimento de competências no uso de uma ferramenta computacional satisfazem os pressupostos delineados.

Desta forma, elaborar, implementar e investigar novos mecanismos educacionais que utilizam as TIC, são necessárias e estão ganhando destaques em pesquisas voltadas ao ensino, como podemos citar: Bento (2010), Vaz (2012), Lopes (2013), Amado, Sanchez e Pinto (2015), Matos e Moraes (2015), entre outros.

Neste sentido, a busca pelo aprimoramento de dinâmicas e recursos auxiliares para o ensino despertam o interesse de docentes em criar estratégias educacionais que atendam os interesses de nossos estudantes, mas ao mesmo tempo cumpram as finalidades da educação escolar (desenvolvimento pleno do estudante, preparo para o exercício da cidadania e qualificação para o trabalho), a fim de contribuir para diminuir as dificuldades apresentadas pelos estudantes em sala de aula. Sabemos que se tratando do aprendizado de conceitos geométricos, em especial, de Geometria e Desenho Geométrico, a maior dificuldade é dada pela falta de contextualização com a realidade dos estudantes. A busca de alternativas que diminuam a falta de relação com situações do cotidiano dos alunos, interdisciplinaridade e ao mesmo tempo contribuam para o desenvolvimento de competências computacionais voltadas aos conhecimentos matemáticos é nossa intencionalidade enquanto docentes e pesquisadores.

Assim sendo, neste trabalho investigamos e avaliamos, através de uma pesquisa quantitativa, como os estudantes dos anos finais do Ensino Fundamental respondem frente a utilização de duas sequências de Atividades Didáticas (AD) computacionais elaboradas e implementadas pelos autores deste artigo. 
No Quadro 1, expomos uma relação das AD conforme numeração, título e anos escolares em que foram aplicadas.

Quadro 1 - Relação das AD numeradas por ano escolar e título, correspondente aos conteúdos abordados nas disciplinas de Geometria e Desenho Geométrico

\begin{tabular}{|l|l|l|l|}
\hline \multicolumn{2}{|c|}{ AD do $8^{\circ}$ Ano - Geometria } & \multicolumn{3}{c|}{ AD do $9^{\circ}$ Ano - Desenho Geométrico } \\
\hline 1. & Retas & 1. & Divisão Proporcional de Segmentos \\
\hline 2. & Mediatriz & 2. & Quarta Proporcional \\
\hline 3. & Ângulos & 3. & Polígonos Semelhantes \\
\hline 4. & Triângulos & 4. & Homotetia \\
\hline 5. & Cevianas Notáveis & 5. & Média Geométrica \\
\hline 6. & Teorema Angular de Tales & 6. & Média Geométrica ou Proporcional \\
\hline 7. & Teorema de Pitágoras & 7. & $\begin{array}{l}\text { Determinação Gráfica da Raiz Quadrada } \\
\text { de Um Número }\end{array}$ \\
\hline 8. & Propriedades dos Triângulos Isósceles & 8. & Expressões Pitagóricas \\
\hline 9. & Concurso "Fazendo Arte no Geogebra" & 9. & Expressões na forma $\sqrt{a^{2} \pm b^{2} \pm c^{2}}$ \\
\hline \multirow{2}{*}{10.} & $\begin{array}{l}\text { Soma dos Ângulos Internos de Um } \\
\text { Quadrilátero Convexo }\end{array}$ & 10. & Concurso "Fazendo Arte no Geogebra" \\
\hline 11. & Número de Ouro & 11. & Equivalência de Triângulos \\
\hline 12. & Retângulo Áureo & 12. & Comparação de Áreas \\
\hline 13. & Simetria & 13. & Equivalência entre Polígonos e Quadratura \\
\hline \multirow{2}{*}{ 14. } & $\begin{array}{l}\text { Posições Relativas de Duas } \\
\text { Circunferências }\end{array}$ & 14. & Transformações Pontuais \\
\hline 15. & Ângulos Inscritos & 15. & Elipse \\
\hline 16. & Curvas Cônicas & 16. & Hipérbole \\
\hline & & 17. & Parábola \\
\cline { 2 - 4 } & 18. & Curvas Cônicas \\
\hline
\end{tabular}

Fonte: Autores.

Todas as atividades do Quadro 1, foram apresentadas, justificadas e analisadas frente ao seu desenvolvimento e viabilidade. $\mathrm{E}$, também argumentadas sobre a necessidade dos estudantes estarem em contato sistemático e periódico com o software Geogebra², em Tibulo e Saurwein (2016). As duas sequências de AD são compostas por 16 atividades para alunos do $8^{\circ}$ ano do Ensino Fundamental e por 18 atividades para alunos do 90 ano do Ensino Fundamental. Estas atividades estão disponíveis em http://boltz.ccne.ufsm.br/st09 e foram elaboradas com objetivo de facilitar a aprendizagem de tópicos de Geometria e Desenho Geométrico e, simultaneamente, promover o desenvolvimento de competências com o software Geogebra. As AD foram estruturadas em sequências relativamente grandes de tarefas para serem realizadas em casa (ou no contra turno), onde os estudantes devem ativamente usar o computador para aprender os conteúdos programáticos que lhes são ensinados de maneira tão natural quanto usam o lápis e papel. Da mesma maneira que o professor ensina o aluno a esboçar gráficos em papel para visualizar, por exemplo, a solução de um sistema de equações lineares, é ensinado aos alunos com a utilização dos recursos computacionais disponíveis para a resolução do problema. As AD investigadas não pretendem substituir tarefas feitas com lápis e papel, mas sim complementá-las. Um arquiteto, por exemplo, usa o papel para esboçar um edifício, mas usa o software CAD para fazer o projeto efetivamente. Como resultados deste trabalho inicial, observamos que as $A D$ foram perfeitamente viáveis. Mostramos que os alunos

\footnotetext{
${ }^{2}$ Acreditamos na necessidade do desenvolvimento de competências em um software de Álgebra e Geometria Dinâmica nos anos finais do Nível Fundamental e que o Geogebra é o aplicativo mais difundido nesta categoria. Dentre os motivos que influenciaram na nossa escolha pelo software Geogebra destacamos dois critérios de escolha: em primeiro lugar, por ser um software livre, pois de outro modo as AD não seriam viabilizadas e em segundo lugar, entre os softwares livres a opção pelo Geogebra pelos seguintes motivos: (1) apresenta uma interface simples e de fácil entendimento; (2) possibilita qualquer construção e representação geométrica, seja ela plana ou espacial, (3) possibilita a exploração, investigação e manipulação rápida dos objetos geométricos; (4) possui um menu completo de ajuda; (5) encontrase disponível no idioma Português.
} 
superaram eventuais dificuldades técnicas (instalação do software Geogebra, acesso às AD no site da Internet e preenchimento de formulário eletrônico) e as entregaram no prazo acordado. Além disso, mostramos que as AD foram dadas em caráter complementar, sem prejuízo dos demais conteúdos programáticos e que os alunos as realizaram com o mesmo comprometimento de outras tarefas de casa.

\section{METODOLOGIA}

Este trabalho tem como objetivo aprofundar a análise da aplicação das sequências de AD com a investigação da receptividade das mesmas pelos alunos que as fizeram, através de uma pesquisa quantitativa cujos dados são oriundos de dois questionários eletrônicos (Questionário da Atividade (QA) e Questionário Final (QF)) respondido pelos 186 estudantes que participaram da implementação das AD. Em nosso grupo de pesquisa Métodos e Processos de Ensino e Aprendizagem de Ciências (MPEAC) os projetos buscam a transformação da própria prática docente e se desenvolvem seguindo uma metodologia de ciclos coordenados, na qual, cada ciclo é composto por etapas estruturantes da Pesquisa Ação, Munn-Giddings (2012), planejamento, ação, observação e reflexão. No projeto no qual se insere este trabalho há três ciclos, denominados Desenvolvimento (D), Viabilidade (V) e Receptividade (R), conforme Figura 1.

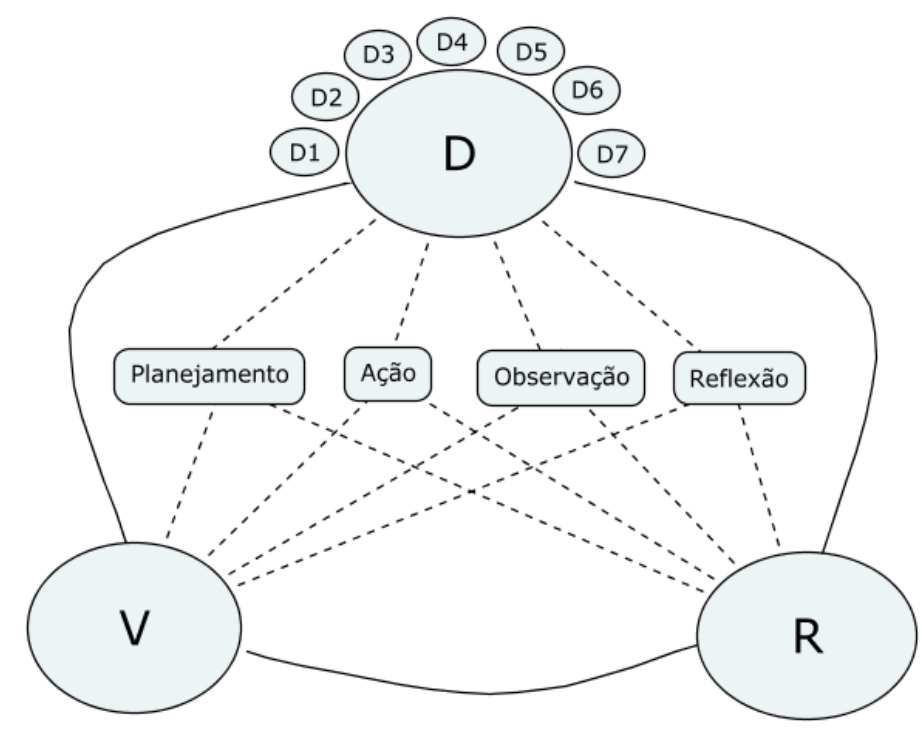

Figura 1 - Diagrama representativo da metodologia de elaboração e análise das Atividades Didáticas

Fonte: Autores.

O ciclo de desenvolvimento das $A D$ parte do princípio de que as atividades deverão buscar a solução de problemas reais vivenciados pelo professor pesquisador. O problema escolhido deve então ser formulado de maneira geral e depois particularizado para as necessidades que serão efetivamente trabalhadas. Neste processo são identificadas as necessidades de curto, médio e longo prazo dos alunos e do professor. Também são feitos detalhamento dos objetivos didáticos pretendidos. Uma vez definido o que se deseja com as $A D$ é iniciado um processo metodológico de Design e desenvolvimento ao final do qual se obtém uma sequência de $A D$ e possíveis procedimentos de implementação. Assim, no ciclo de desenvolvimento seguimos o percurso: (D1) Definição e análise dos objetivos didáticos da AD; (D2) Definição e análise de outros conhecimentos e habilidades necessários para a aprendizagem do tópico principal da AD; (D3) Seleção e criação de recursos didáticos facilitadores para o processo de aprendizagem, como por exemplo: construções gráficas 
realizadas no software Geogebra; (D4) Criação do Design da AD, com planejamento da estrutura completa da $A D$ com suas características (situações-problemas, textos introdutórios, imagens, problemas, questões de reflexão e orientações) e necessidades; (D5) Análise crítica da AD pelos membros do grupo de pesquisa MPEAC/UFSM para verificar sua adequação a pressupostos teóricos, nível de dificuldade, potencialidade para atingir os objetivos propostos; (D6) Inserção do Questionário A (QA) com vistas a balizar o desenvolvimento das $A D$ subsequentes, e posteriormente, também oferecer subsídios para análise da sequência de AD. Neste instrumento, aferimos o trabalho, a dificuldade, o interesse, e de forma geral, a fim de avaliarmos como ocorreu a receptividade dos alunos frente a sequência de $A D$. $O$ instrumento é apresentado aos alunos na forma de uma escala Likert de 5 pontos, conforme ilustrado na Figura 2; e (D7) Implementação através da disponibilidade da $A D$ aos alunos no site: www.ufsm.br/mpeac/vaneza, especialmente desenvolvido para este fim, onde é fixado um prazo para que os alunos a resolvam.

A1) Em sua opinião essa atividade didática computacional foi, em relação ao trabalho:

$\bigcirc 1$ (nada trabalhosa) $\bigcirc 2 \bigcirc 3 \bigcirc 4 \bigcirc 5$ (muito trabalhosa)

A2) Em sua opinião essa atividade didática computacional foi, em relação à dificuldade:

$\bigcirc 1$ (muito fácil) $\bigcirc 2 \bigcirc 3 \bigcirc 4 \bigcirc 5$ (muito difícil)

A3) Em sua opinião essa atividade didática computacional foi, em relação ao interesse:

$\bigcirc 1$ (menos trabalhosas) $\bigcirc 2 \bigcirc 3 \bigcirc 4 \bigcirc 5$ (mais trabalhosas)

A4) Em sua opinião essa atividade didática computacional foi, de forma geral:

$\bigcirc 1$ (fraca) $\bigcirc 2 \bigcirc 3 \bigcirc 4 \bigcirc 5$ (ótima)

Figura 2 - Questionário A respondido pelos alunos ao encerramento de cada AD em relação aos critérios de: trabalho, dificuldade, interesse e de forma geral, com respostas graduadas de 1 a 5 .

Fonte: Autores.

O ciclo D envolve todas as etapas de desenvolvimento e implementação das sequências de $A D$ e ciclo V é composto pelas etapas que buscam mensurar a viabilidade das $A D$, estes dois ciclos são analisados e podem ser observados na íntegra em Tibulo e Saurwein (2016). Já a análise do ciclo R, pelas etapas que buscam caracterizar a receptividade das mesmas, são avaliadas e discutidas neste presente trabalho.

A Figura 3 complementa a Figura 1, em que apresenta um diagrama mais detalhado que ilustra as principais relações que ocorrem nesta metodologia. Neste diagrama as etapas do ciclo D são representadas por círculos azuis, etapas do ciclo $\mathrm{V}$ por retângulos laranjas e do ciclo $\mathrm{R}$ por elipses verdes. O sentido esquerda-direita estabelece a direção do tempo, logo, etapas à direita sucedem etapas à esquerda e etapas alinhadas verticalmente são simultâneas. Cada etapa é identificada pela letra com o nome do ciclo a que pertence no caso $D, V$ ou $R$ (com um sub-índice numérico) e uma sigla com três letras que pode ser PLN, ACT, OBS e RFL, que identificam os seus focos metodológicos que podem ser de, respectivamente, planejamento, ação, observação ou reflexão. As setas em linha sólida indicam o fluxo de tempo, informação ou especificações. Uma etapa planejamento (PLN) ligada por uma seta a uma etapa de ação (ACT) indica que esta ocorre de acordo com as especificações planejadas. A seta que liga a etapa ACT a uma etapa OBS indica que é a ação que 
produz os registros que são organizados na etapa de observação. A seta que liga a etapa OBS à etapa RFL indica que a reflexão ao final de uma execução do ciclo é feita sobre os registros da observação ${ }^{3}$.

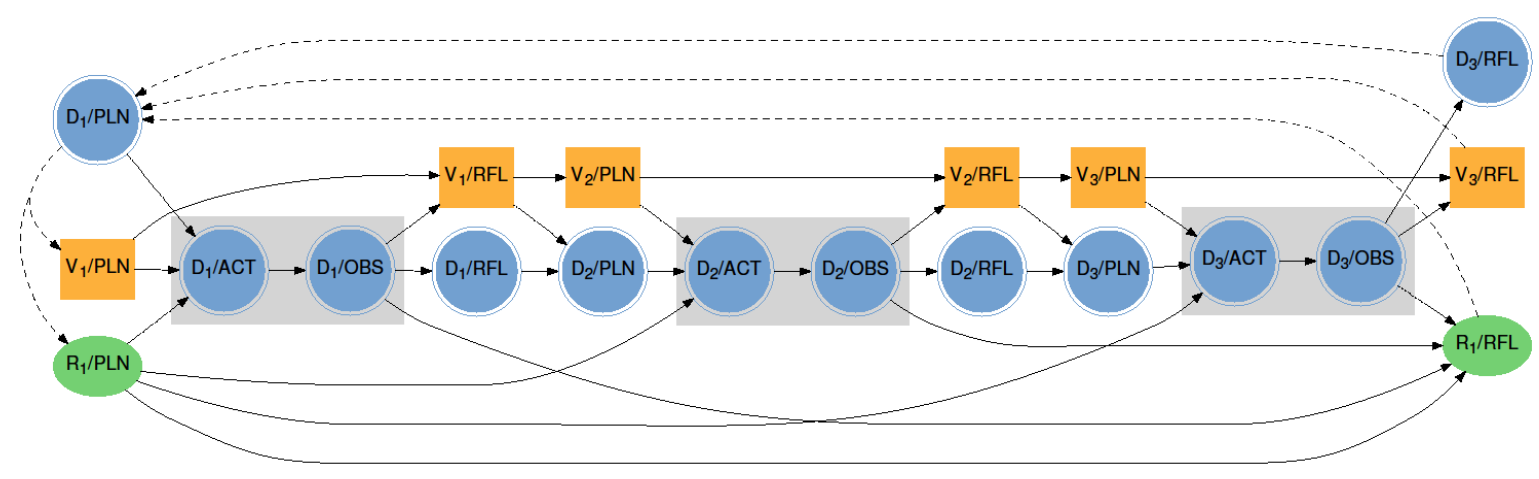

Figura 3 - Diagrama que ilustra as principais relações da metodologia adotada

Fonte: Autores.

Concentrando a atenção para o ciclo $D$ (círculos azuis), é possível ver que as 12 etapas contêm três sequências PLN-ACT-OBS-RFL, o que indica que este diagrama está representando três realizações sucessivas do ciclo de desenvolvimento. O sub-índice da letra que identifica o ciclo é acrescentado para facilitar a identificação da ordem de realização de alguma etapa. Desta maneira, D1/ACT representa a etapa de ação da primeira realização do ciclo de ciclo Desenvolvimento e V2/PLN a etapa de planejamento da segunda realização do ciclo Viabilidade.

O diagrama mostrado na Figura 3 é uma versão resumida dos diagramas reais, pois o desenvolvimento de cada $A D$ da sequência envolve, no ciclo de desenvolvimento, uma sequência PLN-ACT-OBS-RFL. Logo, um diagrama completo mostrando os ciclos metodológicos para a sequência do $8^{\circ}$ ano teria (16x4) círculos azuis, (16x2) quadrados laranjas e duas elipses verdes. Analogamente, no diagrama do 90 ano seriam (18x4) círculos azuis, (18x2) quadrados laranja e duas elipses verdes. Note que os ciclos $\mathrm{V}$ e $\mathrm{R}$ analisam dados coletados nas etapas de observação das repetições do ciclo D. Isto é possível, pois na etapa de planejamento de $\mathrm{V}$ e de $\mathrm{R}$ elaboraram-se os instrumentos e protocolos de pesquisa que foram utilizados nas etapas de ação e observação referidas como sendo ciclo D. Porém, as setas especificam como se dão as relações, dependências e compartilhamento das etapas metodológicas de diferentes ciclos. Além desse compartilhamento, o diagrama resumido também permite observar que os ciclos podem ou não ter o mesmo período. O ciclo $\mathrm{V}$ tem o mesmo período que o ciclo $D$, pois a etapa de planejamento e reflexão do ciclo $D$ há uma etapa correspondente no ciclo $\mathrm{V}$. No entanto o ciclo $\mathrm{R}$ tem período maior que os outros dois, pois a primeira etapa de reflexão do ciclo $\mathrm{R}$ coincide com a última dos demais ciclos. Nos diagramas das Figuras $1 \mathrm{e}$ 3 este trabalho é representado pelo ciclo $R$, ou seja, o ciclo que tem por objetivo fazer uma reflexão sobre a receptividade das $A D$.

Na fase de planejamento, criamos dois instrumentos de coleta de dados. O QA que foi inserido como uma seção extra ao final de cada $A D$, conforme Figura 2, e o Questionário Final (QF) criado como sendo um documento eletrônico a parte das $A D$ e foi planejado para ser respondido como tarefa de encerramento das sequências das $A D$. Em cada questão dos questionários o aluno é convidado a fazer classificações em uma escala de cinco graus, de 1 a 5, usando critérios determinados. A Figura 2

\footnotetext{
${ }^{3} \mathrm{~A}$ etapa PLN especifica todo o processo, logo também a observação e análise. Entretanto para não sobrecarregar a Figura 1, optamos por não representar setas PLN-OBS, e PLN-RFL quando o ciclo contém em si mesmo as quatro etapas (PLN-ACT-OBS-RFL). Por isso no ciclo D estas setas são omitidas, mas nos ciclos V e R, que não têm etapas ACT e OBS próprias, são representadas.
} 
apresenta uma reprodução do QA no qual o aluno deve classificar a $A D$ segundo os critérios de trabalho (questão $A 1$ ), dificuldade (questão $A 2$ ), interesse (questão A3) e de forma geral (questão A4).

O objetivo de solicitar para que os alunos respondam a vários $\mathrm{QA}$, um por atividade é coletar a opinião deles sobre algo que recém terminaram de fazer, ou seja, com memória instantânea e também para verificar eventuais diferenças na receptividade de uma atividade para outra. Por isso as questões do QA são simples e diretas. As três primeiras tratam de aspectos intrínsecos a qualquer tarefa, pois o critério trabalho, dificuldade e interesse estão relacionados, respectivamente, a tempo de realização, complexidade, e capacidade motivadora. A última questão, mais subjetiva, permite que os alunos usem seus próprios critérios para avaliar a AD.

O Questionário Final (QF), representado na Figura 4, possui oito questões divididas em três blocos. As duas primeiras questões compõem o primeiro bloco que tem o objetivo de coletar informações a respeito do prazo disponível (questão F1) e prazo utilizado (questão F2) para a realização das AD. O segundo bloco contém quatro questões nas quais se solicita ao aluno que faça classificações em termos comparativos. A questão F3 requer uma classificação da sequência de AD em termos de sua relação das $A D$ com o conteúdo da disciplina. As demais questões do segundo bloco demandam comparações das AD com as demais atividades regulares das disciplinas de Geometria e Desenho Geométrico (compostas basicamente por problemas e exercícios extraídos do livro). Nesta classificação comparativa, os alunos opinam se as AD foram menos ou mais instrutivas (questão F4), menos ou mais trabalhosas (questão F5) e menos ou mais interessantes (questão F6) que as atividades regulares. Finalmente as duas últimas questões formam um bloco no qual o aluno avalia a contribuição das AD para sua aprendizagem (questão F7) e auto avalia seu desempenho nas mesmas (questão F8).

Para situar o QA e QF no âmbito do projeto de pesquisa, podemos dizer que seu planejamento e elaboração ocorreram na etapa R1/PLN. A inserção de QA ao final de cada AD está representada pelas setas que ligam R1/PLN a todas as etapas ACT do ciclo D. A inserção de QF está representada pela seta que liga R1/PLN a última etapa ACT do ciclo D. A implementação das AD na escola ocorreu segundo as ações previstas nos planejamentos, entre elas, os alunos responderam os QA ao final de cada AD e no encerramento das sequências responderam QF. Os dados gerados seguem para a etapa de reflexão. No diagrama da Figura 3 estes fluxos de informações estão representados pelas setas que ligam todas as etapas de observação do ciclo D com a etapa R1/RFL. Esta reflexão, com o objetivo de investigar a receptividade das $A D$, será feita através de análise estatística na próxima seção. 


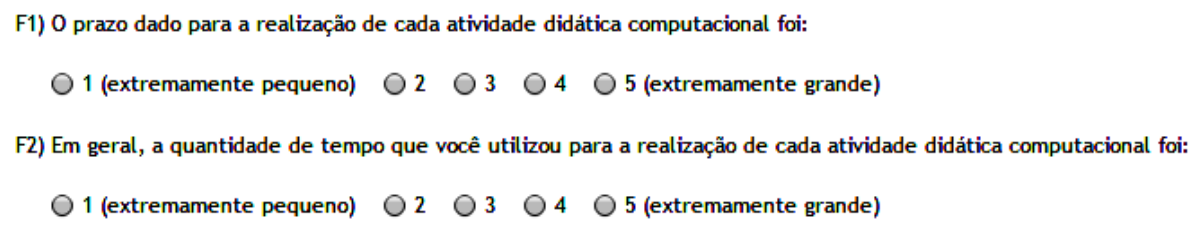

Figura 4 - Questionário F respondido pelos alunos no encerramento das sequências de $A D$, organizado em três blocos de questões.

Fonte: Autores.

\section{RESULTADOS E DISCUSSÃO}

O presente trabalho envolveu 186 estudantes de quatro turmas do $8^{\circ}$ ano e três turmas do $9^{\circ}$ ano do Ensino Fundamental ao longo do ano letivo de 2015, nas disciplinas de Geometria e Desenho Geométrico, em uma instituição pública federal de ensino básico, no Rio Grande do Sul, em que um dos autores é docente destas disciplinas. Esta instituição de ensino oferta Ensino Fundamental (a partir do $6^{\circ}$ ano) e Ensino Médio. Possui estrutura física composta por: salas de aula climatizadas e equipadas com recursos digitais, laboratórios de Informática, Física, Química, Biologia, Matemática, biblioteca, entre outros recursos. Conta também com profissionais da área da educação qualificados com doutorado, mestrado, especialização. Além disso, apresenta particularidades entre elas: heterogeneidade do corpo discente e docente, é regida por um grande número de normas e regras, principalmente de disciplina, entre outras.

No cenário nacional esta instituição tem se destacado pelos resultados obtidos nas avaliações nacionais como Prova Brasil e Exame Nacional do Ensino Médio (ENEM), pelo grande número de egressos aprovados nos mais diversos concursos e vestibulares em universidades públicas e particulares e também pelo bom desempenho nas olimpíadas de Matemática, Física, Química, Língua Portuguesa, Geografia e Astronomia. 
Outro diferencial desta instituição é sua uniformidade de procedimentos de ensino regida por normas, regimentos e regulamentos que asseguram aos alunos uma rápida adaptação e aos professores uma diretriz do caminho a ser percorrido durante todo o processo. Como exemplos podemos citar: uniformidade da grade curricular de todas as instituições que fazem parte deste sistema no âmbito nacional, acompanhamento contínuo de coordenadores de ano e de disciplinas nas etapas de elaboração/planejamento e execução das aulas, bem como, das avaliações realizadas ao longo do processo de ensino, cobrança da participação da família e responsáveis na vida escolar dos estudantes.

\subsection{Receptividade Geral}

A análise das opiniões dos alunos permite inferir o grau de receptividade da sequência de AD como um todo. Estas opiniões foram coletadas no questionário QF apresentado na seção metodologia.

\section{O primeiro bloco do questionário $\mathrm{F}$ avalia a receptividade em relação ao prazo disponível} e tempo realização. Uma receptividade positiva dos alunos em relação ao prazo e tempo de realização das $A D$ é fundamental para que as mesmas se estabeleçam de forma permanente. As respostas à questão $F 1$, sobre o prazo disponível para realizar as $A D$ e à questão F2, sobre o tempo necessário para realizá-las permitem inferir esta receptividade. A Tabela 1 apresenta os valores médios respondidos a estas duas questões com os respectivos desvios4.

Tabela 1 - Valores médios das respostas às questões F1 e F2 nas quais os alunos classificam, respectivamente, as AD quanto ao prazo disponível para realiza-las e o tempo de realização

\begin{tabular}{ccc}
\hline Ano & Prazo para realizar (F1 médio) & Tempo de realização (F2 médio) \\
\hline $8^{\circ}$ ano & $2,85(6)$ & $3,13(6)$ \\
90 ano & $3,09(6)$ & $3,07(7)$ \\
\hline
\end{tabular}

Fonte: Autores.

Os valores da Tabela 1 estão bastante próximos do valor 3, logo, em média, o prazo e o tempo de realização foram considerados pelos estudantes adequados (nem grandes nem pequenos).

Para uma análise cruzada entre as respostas de F1 e F2 apresentamos a Tabela 2 na qual cada linha seleciona os alunos conforme a faixa de resposta em F2 (tempo de realização). Nesta Tabela 2 a quarta e quinta coluna apresentam, respectivamente, os valores médios respondidos na questão $\mathrm{F} 1$, pelos alunos do $8^{\circ}$ e $9^{\circ}$ ano por faixa de resposta em F2. A Faixa F2>3 corresponde aos alunos que responderam 4, ou 5 à questão F2, logo, são os alunos que consideraram o tempo de realização grande, ou extremamente grande, o que em princípio, poderia ser interpretado como sendo um aspecto negativo das AD. Apenas $21,0 \%$ do $8^{\circ}$ ano e $19,8 \%$ do $9^{\circ}$ ano, cerca de $1 / 5$ dos alunos, consideraram que as AD estavam nesta faixa. Nesta faixa, o valor médio respondido na questão F1 foi, respectivamente, de 2,71 e 3,00 para as turmas do $8^{\circ}$ e $9^{\circ}$ ano. Portanto, os $19,8 \%$ dos alunos do $8^{\circ}$ ano que consideraram as tarefas longas, julgaram, em média, que o tempo disponível foi ligeiramente menor que o adequado (o valor 2,71 é cerca de $10 \%$ deslocado do valor central 3,00). Logo, pode-se argumentar que para um quinto dos alunos do $8^{\circ}$ ano, um pouco mais de tempo disponível para a realização das tarefas seria bem-vindo. Os $21 \%$ dos alunos do $9^{\circ}$ ano da faixa F2>3, responderam em média 3,00 para a questão F1, logo, apesar de julgarem longo o tempo de realização consideraram os prazos disponíveis adequados.

\footnotetext{
${ }^{4}$ Neste trabalho os desvios estatísticos, quando calculados, são dados entre parênteses e incidem sobre os últimos algarismos significativos representados.
} 
Tabela 2 - Respostas das questões de F1 e F2 para análise cruzada entre estas questões, onde cada linha seleciona os alunos conforme a faixa de resposta em F2 (tempo de realização)

\begin{tabular}{lcccc}
\hline Faixa & Percentual turmas & Percentual turmas & F1 médio $8^{\circ}$ & F1 médio 90 \\
(tempo de realização) & $8^{\circ}$ ano & 90 ano & ano & ano \\
\hline Pequeno (F2<3) & $8,0 \%$ & $12,8 \%$ & 2,62 & 3,36 \\
Médio (F2=3) & $71,0 \%$ & $67,4 \%$ & 2,92 & 3,07 \\
Grande (F2>3) & $21,0 \%$ & $19,8 \%$ & 2,71 & 3,00 \\
\hline
\end{tabular}

Fonte: Autores.

Na Tabela 2 pode-se ver que a grande maioria dos estudantes, $71 \%$ do $8^{\circ}$ ano e $67,4 \%$ do $9{ }^{\circ}$ ano, ou seja, cerca de $2 / 3$ das turmas julgaram o tempo de realização adequado e apenas uma minoria, $8,0 \%$ do $8^{\circ}$ ano e $12,8 \%$ do $9^{\circ}$ ano, julgaram que realizaram a tarefa em tempo curto. Em relação a estas duas faixas, que concentram a maioria dos estudantes $79 \%$ dos alunos do $8^{\circ}$ ano e $87,2 \%$ do 90 ano, o tempo de realização das AD não pode ser considerado um empecilho, muito pelo contrário, pois $A D$ buscam promover uma mudança significativa na prática dos estudantes através de realização de tarefas em que eles têm que aprender também a usar um novo recurso computacional (Geogebra). Logo, é desejável que as AD sejam consideradas medianas quanto ao tempo de realização, pois este tempo é o momento em que usam a ferramenta computacional e no qual efetivamente desenvolvem competências na mesma. Portanto, em relação ao aspecto tempo de realização, consideramos que as $\mathrm{AD}$ tiveram uma receptividade positiva.

O segundo bloco do questionário $F$ investiga a receptividade comparativa das $A D$. Ao responder ao segundo bloco do questionário F, questões F3, F4, F5 e F6, após terem realizado todas as sequências de $A D$, portanto no final do ano letivo, os alunos podem fazer um julgamento no qual têm condições de comparar o conteúdo abordado nas $A D$ com o conteúdo teórico da disciplina. Também têm condições de comparar as tarefas propostas nas $A D$ com as tarefas regulares normalmente dadas na disciplina. Desta forma, as respostas a estas perguntas permitem avaliar a receptividade das $A D$ pelos estudantes em termos comparativos. A Figura 5 apresenta o histograma das respostas dadas. Na seção metodologia vimos que a questão F3 mede a percepção dos alunos em relação com o conteúdo programático e as questões F4, F5 e F6, medem, respectivamente, a percepção, em menor ou maior grau, da capacidade de instrução, trabalho necessário para realização e interesse despertado pelas AD em comparação com as atividades regulares.

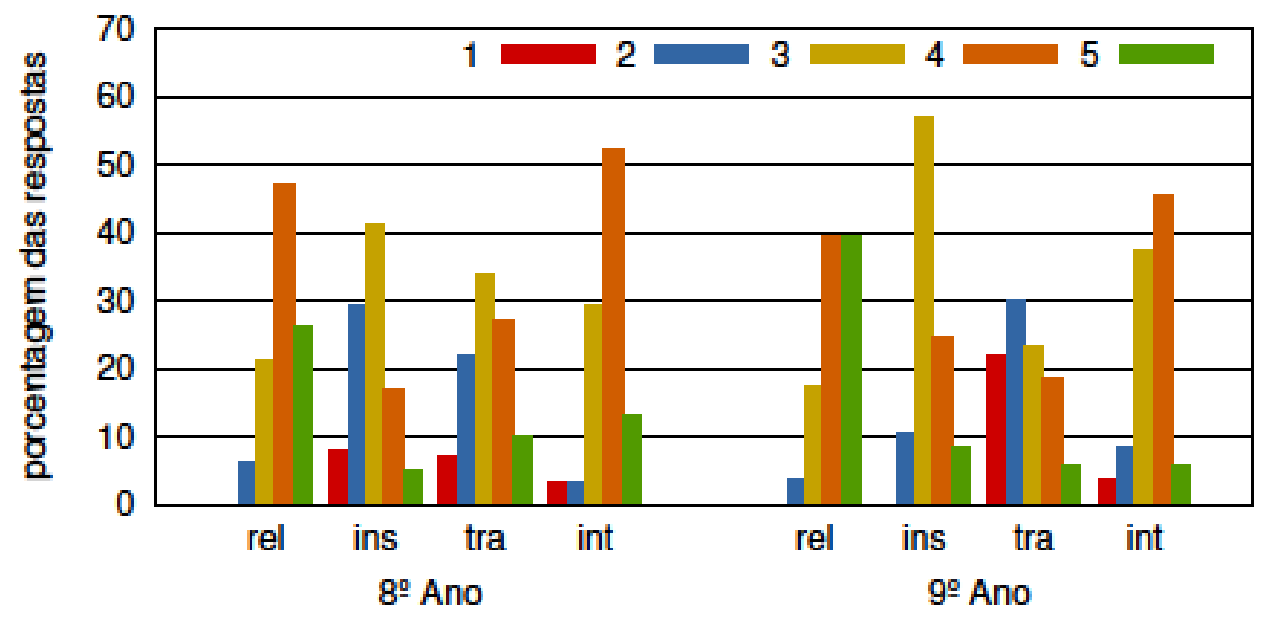

Figura 5 - Histogramas das respostas às questões F1(rel), F4 (ins), F5 (tra) e F6 (int). F3 requer a classificação em termos do nível de relação com o conteúdo

Fonte: Autores. 
Dada a proposta das $A D$ a percepção da relação com o conteúdo é uma condição necessária para avaliar sua pertinência. Este aspecto é medido pela questão F3, no qual pode-se perceber claramente que os alunos dos dois anos majoritariamente fazem esta relação. De fato, como se pode ver na Figura 4 não houve resposta com $\mathrm{F} 3=1$, ou seja, todos perceberam alguma relação das $A D$ com o conteúdo da disciplina. Também se pode observar a faixa da mediana para muita relação com o conteúdo, F3 $\geq 3$, contém praticamente a grande maioria das respostas. De fato, nesta faixa, responderam $94,0 \%$ dos alunos do $8^{\circ}$ e $96,5 \%$ dos alunos $9^{\circ}$ ano. O valor médio das respostas dadas à questão F3 foram, respectivamente para os $8^{\circ}$ e $9^{\circ}$ ano, 3,93(8) e 4,15(9). Estes valores estão claramente deslocados para o lado de uma percepção de alta relação com o conteúdo. Logo, pelo critério da relação com o conteúdo podemos dizer que as $A D$ atingiram um de seus objetivos.

As respostas dadas à questão $\mathrm{F} 4$ mostram que os alunos do 90 ano tiveram uma opinião mais favorável às $A D$, em relação à sua capacidade instrutiva, do que os alunos do $8^{\circ}$ ano. Enquanto $32,6 \%$ dos alunos do 90 consideraram as $A D$ mais instrutivas que as atividades regulares, apenas $22,0 \%$ dos alunos do $8^{\circ}$ ano tiveram a mesma opinião. Como pode ser visto na Figura 5, as opiniões de ambas as turmas nesta questão se concentraram no valor $F 4=3$, que classifica as AD como sendo tão instrutivas quanto às atividades regulares. Opinaram desta maneira $57,0 \%$ do 90 ano e 41,0 do $8^{\circ}$ ano. O contraste entre a opinião dos dois anos é maior quando se compara aqueles que consideraram as $A D$ menos instrutivas que as $A D$ regulares, $37,0 \%$ do $8^{\circ}$ ano e apenas $10,5 \%$ do $9^{\circ}$ ano. Os valores médios de F3 para $8^{\circ}$ e $9^{\circ}$ ano foram respectivamente $2,82(10)$ e 3,30(8), que naturalmente refletem a diferença de opinião observada nos histogramas das duas turmas.

Uma possível razão para a discrepância entre as opiniões do $8^{\circ}$ e $9^{\circ}$ ano em relação à capacidade instrutiva das AD talvez possa ser explicada em termos do conteúdo de cada ano. № $8^{\circ}$ ano foram abordados os primeiros conceitos da Geometria que por estarem ligados às noções intuitivas são facilmente assimilados. No $9^{\circ}$ ano os conceitos e operações são mais complexos e seu entendimento é de fato facilitado pela interface de geometria dinâmica (capacidade de manipulação de representação de entidades geométricas) do Geogebra. Apesar da fração de $37 \%$ dos alunos do $8^{\circ}$ ano que consideraram as $A D$ menos instrutivas ser significativo5 acreditamos que a aplicação das $A D$ neste nível se justifica, pois $63 \%$ do $8^{\circ}$ ano consideraram as $A D$ pelo menos tão instrutivas quanto as demais tarefas e há vantagens pedagógicas inerentes ao uso de diversos recursos didáticos.

A opinião em relação à carga de trabalho foi indiretamente abordada nas questões $F 1$ e $F 2$, mas naquele momento, solicitou-se uma classificação segundo as concepções do próprio aluno. À diferença de F2 a questão F5 está na solicitação ao aluno de comparar as AD com os problemas e exercícios que normalmente fazem na disciplina. Desta maneira, mesmo opinando que todas as tarefas das disciplinas são trabalhosas, os estudantes podem informar se consideram as AD mais ou menos trabalhosas que sua congênere em lápis e papel.

Na Figura 5, os histogramas da questão F5 que comparam a carga de trabalho mostram que as respostas foram bastante distribuídas em todos os graus de classificação. Nestes histogramas, a fração dos alunos que consideraram as $A D$ de menos trabalhosa a tão trabalhosa quanto ( $F 5 \geq 3$ ) compõem a maioria dos alunos $63,0 \%$ do $8^{\circ}$ ano e $75,6 \%$ do $9^{\circ}$ ano. Na turma do $9^{\circ}$ ano a fração de alunos que considerou as $A D$ mais trabalhosas é relativamente pequeno, $24,4 \%$, mas no $8^{\circ}$ ano

\footnotetext{
${ }^{5}$ Em geral frações de até $10 \%$ com respostas desfavoráveis em atividades com características destas AD (numerosas, individuais, relativamente trabalhosas, e obrigatórias), em primeiras implementações, são consideradas normais. Por isso a fração dos alunos do 90 ano com esta opinião não desperta, neste momento, maiores preocupações.
} 
eles formam uma minoria significativa 37\%. No entanto, os valores médios da resposta em F5 nas duas turmas, são para o $8^{\circ}$ e $9^{\circ}$ ano, respectivamente, 3,11(11) e 2,26(13). Desta forma, vemos que o valor médio para o $8^{\circ}$ está muito próximo de 3 (tão trabalhosa quanto) e do $9^{\circ}$ significativamente abaixo de 3, logo, podemos concluir que em relação à carga de trabalho, em média, a receptividade das $A D$ foi semelhante às atividades regulares.

A última questão do segundo bloco do questionário $F$, F6, solicita para o aluno classificar as AD comparativamente às atividades regulares em relação ao que consideram interessantes. Este critério é bastante subjetivo, pois o interesse sobre algo está ligado as preferências individuais também naturalmente subjetivas. No entanto podemos argumentar que é um critério importante, pois se relaciona com a capacidade motivadora da AD. Os histogramas da Figura 5 referentes à questão F6 claramente mostram que os alunos julgaram as $A D$ positivamente. Julgaram mais interessantes (F5>3) $65,0 \%$ do $8^{\circ}$ ano e $51,2 \%$ do 90 . Opinaram que as AD eram tão interessantes quanto as atividades regulares ( $F 6=3$ ), $29,0 \%$ do $8^{\circ}$ ano e $37,2 \%$ do $9^{\circ}$ ano. Apenas $6 \%$ do $8^{\circ}$ ano e $11,6 \%$ do 90 ano consideraram as $A D$ menos interessantes (F6<3). Os valores médios das respostas dadas à F6, são para o $8^{\circ}$ e $9^{\circ}$ ano, respectivamente, 3,69(8) e 3,42(9), que classificam as $A D$ significativamente na faixa de opinião que considera as $A D$ mais interessantes que as $A D$ regulares ( $F>3$ ). Portanto, podemos concluir que a receptividade dos alunos em relação a um aspecto motivador foi significativamente positiva.

\section{O terceiro bloco do questionário $F$ avalia, na opinião dos alunos, a contribuição das AD} para suas aprendizagens. As questões F7 e F8 do terceiro bloco do questionário $F$ estão diretamente relacionadas, pois os alunos devem avaliar quanto as $A D$ contribuíram para a aprendizagem dos tópicos da disciplina (F7) e como avaliam seu desempenho nas mesmas (F8). De fato, a correlação de Pearson entre as duas respostas é 0,49 para o $8^{\circ}$ ano e 0,51 para o $9^{\circ}$ ano. Nos histogramas de duas variáveis (respostas de F7 e F8) da Figura 6 apresenta a porcentagem de alunos que responderam a cada uma das 25 possibilidades de combinações de valores das respostas de F7 e F8. É possível verificar que a distribuição de maior frequência se encontra ao longo da diagonal quando $|\mathrm{F} 8-\mathrm{F} 7| \leq 1$, ou seja, quando as respostas dadas a F8 e F9 diferem por no máximo um grau. Nesta faixa de proporcionalidade com 13 dos 25 pontos do diagrama estão 85,0\% das respostas do $8^{\circ}$ ano e $86,4 \%$ do $9^{\circ}$ ano. Os valores médios para a contribuição das AD na aprendizagem foram, respectivamente, para o $8^{\circ}$ e 90,3,26(12) e 3,26(11), consideradas toda a amostra. Um resultado que consideramos interessante é avaliar apenas a faixa dos alunos que têm um desempenho proporcional à aprendizagem. Esta faixa é composta pelos alunos que satisfazem a hipótese de que o desempenho e aprendizagem estão correlacionadas. Nesta faixa, os valores médios das respostas da contribuição para a aprendizagem são 3,33 para o $8^{\circ}$ ano e 3,30 para o $9^{\circ}$ ano, ou seja, ligeiramente maiores que as médias sobre toda a amostra. Em síntese, estes resultados mostram que na opinião dos alunos as AD contribuíram para suas aprendizagens. 

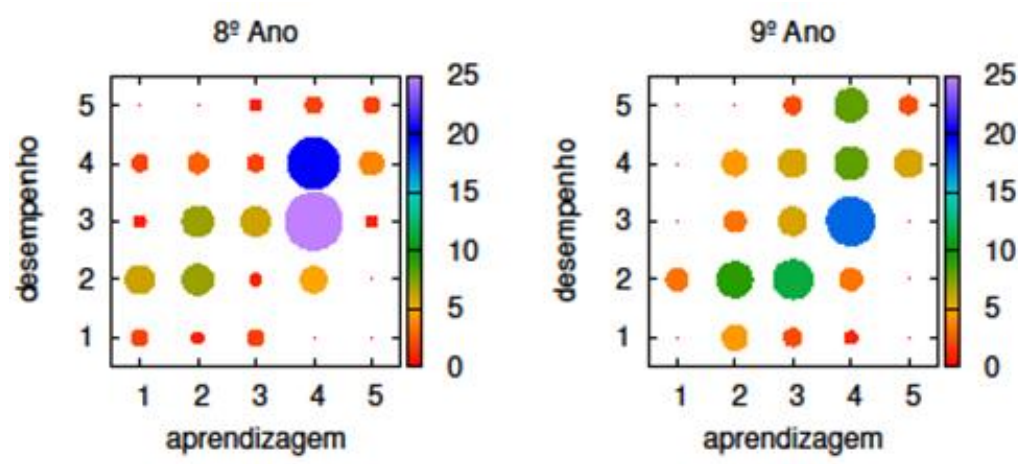

Figura 6 - Histogramas de duas variáveis das respostas da questão F7 (aprendizagem) cruzadas com as respostas da questão F8 (desempenho) para cada ano. O tamanho (área) de cada símbolo e a escala de cores define a porcentagem de alunos que responderam os valores histogramados. Por exemplo, no histograma do $8^{\circ}$ ano, o círculo azul no ponto $(4,4)$ indica que a resposta F7=4 e F8=4 ocorreram, (simultaneamente), $25 \%$ das vezes no questionário $\mathrm{F}$ do $8^{\circ}$ ano.

Fonte: Autores.

\subsection{Receptividade de cada AD}

O questionário A é aplicado ao final de cada AD, logo, as respostas captam as opiniões dos alunos ao longo do processo. As questões deste questionário, apresentado na seção metodologia, requerem classificações em relação à carga de trabalho (questão A1), grau de dificuldade (questão A2), grau interesse (questão A3) e nota geral da tarefa (questão A4). Estas questões são bem gerais e fornecem indicativos a respeito de aspectos essenciais para a realização das $A D$. Por exemplo, considerando que as sequências de $A D$ são longas, se cada $A D$ é considerada muito trabalhosa, dificilmente os alunos teriam condições de realizar todas elas. Na Figura 7 apresentamos os valores médios respondidos pelos alunos, nos quais se pode observar que os valores variam bastante de AD para AD. Visualmente, percebe-se que a dispersão dos valores do $8^{\circ}$ ano são maiores que do $9^{\circ}$ ano. Esta variação deve ser em grande parte, devida à variação nos tópicos de conteúdo ou competências que são abordados e que foram determinados pela necessidade da coordenação das AD com o restante das disciplinas.
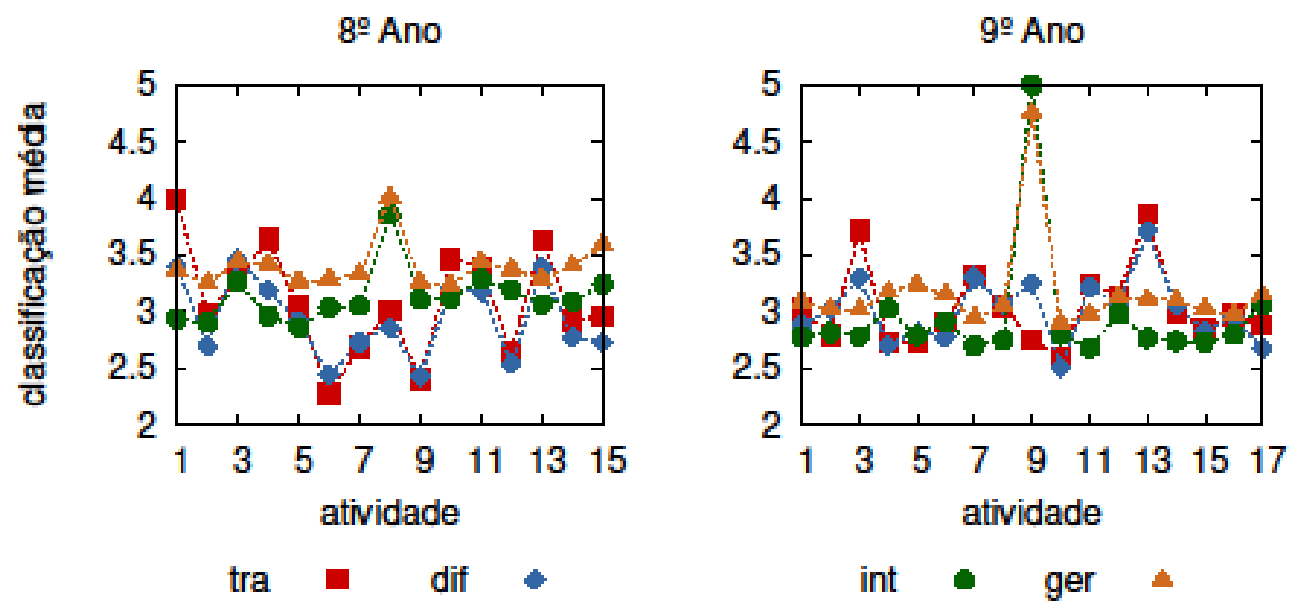

Figura 7 - Gráficos com as médias das respostas do Questionário A de cada atividade didática Fonte: Autores.

Na Tabela 3, apresentamos os valores máximos, mínimos, desvios-padrão e os valores médios dos pontos apresentados no gráfico da Figura 7. Nesta tabela estão desconsideradas duas atividades de caráter optativo ( $A D 9$ do $8^{\circ}$ ano e a $A D 10$ do $9^{\circ}$ do ano) que foram realizadas no período de férias por poucos alunos. Claramente, a opinião sobre estas AD optativas destoa das demais e por isso foram descartadas da análise. Os desvios-padrão medem a dispersão dos pontos, logo, pode-se ver 
que as maiores variações, de $A D$ para $A D$, estão relacionadas à carga de trabalho e dificuldade, tanto no $8^{\circ}$ quanto no $9^{\circ}$ ano. A dispersão no interesse e na nota geral é muito menor que o trabalho e dificuldade. Uma possível explicação para esta diferença de comportamento é que o trabalho e dificuldade variam com os tópicos das disciplinas abordados, há tópicos mais difíceis e trabalhosos que outros. Já o interesse está mais ligado à afinidade dos alunos com as disciplinas e, ou com proposta das $A D$, por isso varia menos de $A D$ para $A D$.

Tabela 3 - Valores máximos, mínimos, desvios-padrão e os valores médios dos pontos apresentados no gráfico da Fig. 7

\begin{tabular}{lcccccccc}
\hline & $\mathrm{A} 1 / 8$ & $\mathrm{~A} 2 / 8$ & $\mathrm{~A} 3 / 8$ & $\mathrm{~A} 4 / 8$ & $\mathrm{~A} 1 / 9$ & $\mathrm{~A} 2 / 9$ & $\mathrm{~A} 3 / 9$ & $\mathrm{~A} 4 / 9$ \\
\hline Min & 2,27 & 2,43 & 2,86 & 3,22 & 2,60 & 2,51 & 2,68 & 2,90 \\
Max & 3,99 & 3,46 & 3,29 & 3,59 & 3,85 & 3,71 & 3,06 & 3,24 \\
Desvio & 0,50 & 0,36 & 0,13 & 0,10 & 0,34 & 0,30 & 0,12 & 0,09 \\
Sterr & 0,04 & 0,04 & 0,04 & 0,03 & 0,04 & 0,04 & 0,04 & 0,07 \\
\hline Med & $3,10(4)$ & $2,93(4)$ & $3,08(4)$ & $3,35(3)$ & $3,03(4)$ & $2,98(4)$ & $2,83(4)$ & $3,07(4)$ \\
\hline \multicolumn{7}{c}{ Fonte: Autores. }
\end{tabular}

Em relação ao trabalho e dificuldade, de acordo com a Tabela 3, os alunos do $8^{\circ}$ e 90 ano julgaram as $A D$ próximas da classificação neutra, respectivamente, com $A 1=3,10(4)$ e $A 2=2,93(4)$ para $8^{\circ}$ ano e $A 1=3,03(4)$ e $A 2=2,98(4)$ para o $9^{\circ}$ ano. Considerando estas grandezas dentro do desvio estatístico, vemos que as duas turmas tiveram a mesma opinião para os níveis de trabalho e dificuldade. Estes valores mostram a adequação das $A D$ em relação a estes dois parâmetros, pois em uma sequência numerosas de tarefas é normal a alternância do nível de dificuldade e trabalho, mas é sempre aconselhável que oscilem em torno de uma valor médio aceitável pelos alunos.

Em relação ao interesse há uma pequena discrepância entre as duas turmas. Na opinião do $8^{\circ}$ ano, o valor do interesse médio é $A 3=3,08(4)$, que está bastante próximo de um interesse mediano. Este mesmo valor para a turma do 90 ano é $A 3=2,83(4)$, ou seja, na opinião média desta turma as $A D$ estão ligeiramente na parte negativa na classificação interesse, ou em outras palavras, seriam ligeiramente desinteressantes. Esta discrepância de julgamento entre as duas turmas se acentua quando se compara os valores referentes à nota geral média atribuída. Para $8^{\circ}$ ano, o valor médio da nota geral é $A 4=3,35(3)$, ou seja, avaliação significativamente positiva, enquanto para o 90 ano é $A 4=3,07(4)$, que, apesar estar no lado positivo da classificação, está muito próximo de seu valor neutro.

Também podemos analisar as respostas dadas às questões $A 1, A 2, A 3$ e A4 através dos histogramas apresentados na Figura 8. Nesta Figura é possível ver que o valor neutro se destaca em todos os histogramas e picos bem pronunciados só aparecem nos histogramas da questão A4 (ger). Excetuando-se este histograma, nos demais, a fração de alunos que responde positivamente (graus 3 e 4) é aproximadamente igual à que responde negativamente (1 e 2), de forma que em relação ao trabalho, dificuldade e interesse, as opiniões se dividem em frações mais ou menos do mesmo tamanho, que por sua vez é aproximadamente do mesmo tamanho que o valor neutro. Desta forma, a opinião dos alunos dividiu-se em partes aproximadamente equivalentes de classificações positiva, negativa e neutra em relação aos critérios trabalho, dificuldade e interesse. Estes resultados, de certa forma são esperados, pois as sequências das AD são grandes e variadas. 


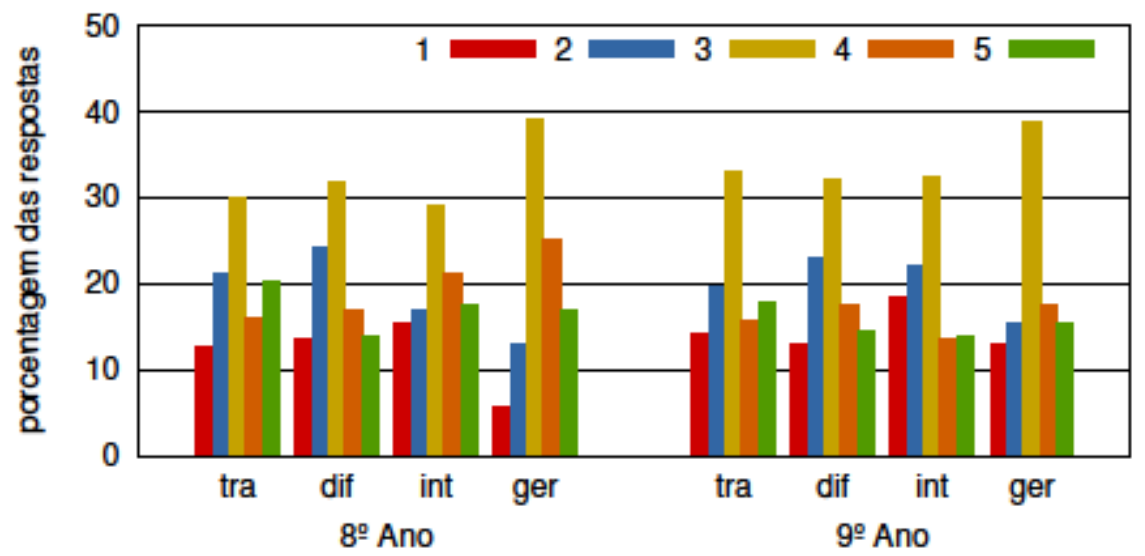

Figura 8 - Histogramas onde tra, dif, int e ger correspondem, respectivamente, à classificação quanto ao trabalho, dificuldade, interesse e de forma geral

Fonte: Autores.

É interessante comparar os resultados das respostas da questão A1 com a questão F6 que também requer uma classificação em relação trabalho, porém comparativa às demais tarefas das disciplinas. A opinião média da turma do $8^{\circ}$ ano é praticamente a mesma nas duas questões $(3,10(4)$ em $A 1$ e 3,11(11) em F6), e da turma do 90 ano é significativamente diferente (3.03(4) em A1 e 2.26(13) em F6). Lembrando que um valor neutro em F6 significa que as AD foram tão trabalhosas quanto as demais tarefas das disciplinas, para os alunos do $9^{\circ}$ é possível argumentar que há espaço para tornar as tarefas tradicionais ligeiramente mais trabalhosas.

Outra comparação pertinente pode ser dada entre os resultados do interesse despertado pelas $A D$ que é abordado nas questões F6 e A3. Na questão F6, quando a comparação do interesse despertado pelas $A D$ é feita em relação às outras tarefas de Geometria e Desenho Geométrico, os alunos expressam uma opinião bastante favorável às $A D\left(3,69(8)\right.$ no $8^{\circ}$ ano e 3,42(9) no $9^{\circ}$ ano). No entanto, como a questão A3 não limita o campo de classificação ao domínio dos assuntos abordados nas disciplinas, o interesse médio despertado foi bem mais baixo (3,08(4)/80 ano e $2,83(4) / 9^{\circ}$ ano). Este resultado é compreensível pois a questão A3 também capta o interesse ou desinteresse dos alunos pelo conteúdo das $\mathrm{AD}$ (e das disciplinas) e não somente as características inovadoras das mesmas (estrutura, tipo de questões e uso do Geogebra).

\section{CONSIDERAÇÕES FINAIS}

Neste trabalho analisamos a receptividade de duas sequências de AD, baseadas na utilização das TIC, sendo $16 A D$ para o $8^{\circ}$ ano e $18 A D$ para o $9^{\circ}$ ano do Ensino Fundamental que cobrem praticamente todo o conteúdo do ensino de Geometria e Desenho Geométrico dos respectivos anos escolares. Nossa análise focalizou aspectos que julgamos essenciais para que as AD sejam realizadas pelos estudantes, a saber: carga de trabalho, dificuldade, interesse, capacidade instrutiva e relação com conteúdo programático. O resultado da análise mostra que, através da receptividade dos alunos em relação a estes aspectos, as AD podem ser incorporadas de forma permanente na prática escolar.

Consideramos importante à análise da receptividade na implementação de novas práticas na escola, pois de outro modo, resistências dos estudantes em relação a eventuais inovações podem comprometer a mudança desejada. 
Investigamos e avaliamos esta proposta didática através de sua aplicação ao longo do ano letivo de 2015 em quatro turmas de $8^{\circ}$ ano e três turmas de $9^{\circ}$ ano do Ensino Fundamental em que um dos autores é docente das disciplinas de Geometria e Desenho Geométrico de uma instituição pública federal de ensino básico, totalizando a participação de 186 estudantes.

A receptividade das $A D$ foi feita analisando-se 186 questionários $Q F$, respondidos ao término da aplicação das duas sequências de AD (186 estudantes) e, aproximadamente 6324 questionários QA, respondidos ao término de cada $A D$ (34 $A D$ x 186 estudantes). O QF é composto por três blocos de questões. No primeiro bloco investigamos o prazo e tempo, no segundo bloco, analisamos uma classificação comparativa entre relação, instrução, trabalho e interesse e no último bloco, analisamos a contribuição e desempenho. O QA é composto com quatro questões simples onde o estudante deveria classificar as AD em uma escala de 5 pontos, de 1 ao 5, nos critérios de trabalho, dificuldade, interesse e de forma geral.

A análise dos questionários QF respondidos ao término da aplicação das sequências de $A D$ mostra o prazo e tempo de realização das $A D$ foram considerados pelos alunos adequados. Os estudantes dos dois anos majoritariamente perceberam a relação das $A D$ com os conteúdos trabalhados em sala de aula, com valor médio das respostas, respectivamente para o $8^{\circ}$ ano e $9^{\circ}$ ano, 3,93(8) e 4,15(9), logo, pelo critério da relação com o conteúdo podemos afirmar que as $A D$ atingiram um de seus objetivos. Em relação a capacidade instrutiva, verificamos uma discrepância entre os dois anos, sendo que o $9^{\circ}$ ano teve uma opinião mais favorável às $A D$ do que o $8^{\circ}$ ano, $32,6 \%$ e $22 \%$, respectivamente consideram as $A D$ mais instrutivas que as demais atividades. Diante da carga de trabalho, as $A D$ foram mais ou menos trabalhosas, semelhantes às atividades regulares de lápis e papel. $A$ receptividade dos alunos em relação a um aspecto motivador foi significativamente positiva. Os resultados também apontam que as $A D$ contribuíram para a aprendizagem dos estudantes.

A análise dos questionários QA aplicados ao final de cada $A D$ mostra que as $A D$ foram consideradas com níveis de dificuldade e carga de trabalho compatíveis com o esperado para uma sequência de $A D$ que se incorporou a pratica escolar de maneira permanente. Analisando como um todo, vemos que as $A D$ estão bem balanceadas em termos de trabalho e dificuldade e que se posicionaram positivamente em relação ao interesse e impressão de forma geral.

Em síntese concluímos que as sequências de $A D$ podem ser uma alternativa viável e interessante para ser aplicada em consonância com as atividades e conteúdos regulares trabalhados em sala de aula sem comprometer o andamento e cronograma escolar.

\section{REFERÊNCIAS}

AMADO, N.; SANCHEZ, J.; PINTO, J. A Utilização do Geogebra na Demonstração Matemática em Sala de Aula: o estudo da reta de Euler. Bolema, Rio Claro (SP), v. 29. n. 52. p. 637-657, ago 2015.

BENTO, H. A. O desenvolvimento do pensamento geométrico com a construção de figuras geométricas planas utilizando o software: Geogebra. 2010. 260 p. Dissertação (Mestrado em Ensino de Ciências e Matemática) - Pontifícia Universidade Católica (PUC), Belo Horizonte, MG, 2010.

LOPES, M. M. Sequência Didática para o Ensino de Trigonometria Usando o Software Geogebra. Bolema, Rio Claro (SP), v. 27, n. 46, p. 631-644, agosto 2013. 
MATOS, T. F. C.; MORAES, L. F. Ensino de Geometria apoiada por TIC: Uma abordagem metodológica baseada na coletividade e significação dos conceitos utilizando Geogebra. XII Semana de Licenciatura. III Seminário de Pós-Graduação em Educação para Ciências e Matemática. I Encontro de Egressos do Mestrado. Jataí, GO, 13 a 16 de outubro de 2015.

MUNN-GIDDINGS, C. Action research. In: ARTHUR, J.; WARING, M.; COE, R.; HENDGES, L. V. (Coord.). Research Methods \& Methodologies in Education. SAGE. Los Angeles, London, New Delhi, Singapore e Washington DC. 2012.

PRENSKY, M.: Digital Natives, Digital Immigrants. In: PRENSKY, Marc. On the Horizon. NCB University Press, Vol. 9 No. 5, October (2001). Disponível em <http://www.marcprensky.com/writing/>. Acesso em 1/Maio/2017.

TIBULO, V. D. C.; SAUERWEIN, R. A. Sequência de atividades didáticas para o ensino de Geometria e Desenho Geométrico com ênfase no desenvolvimento de competências. Revista Dynamis. Blumenau (SC), v. 22, n. 1, p. 14-32, 2016.

VAZ, D. A. F. Experimentando, conjecturando, formalizando e generalizando: articulando investigação Matemática com o Geogebra. Educativa. Goiânia, v. 15, n. 1, p. 39-51, jan/jul 2012. 